\title{
Demographic Profile of Hand Injuries in North India: A Tertiary Care Hospital Experience.
}

\author{
Sandesh Bharat Singh ${ }^{1 *}$, Harsha Vardhan ${ }^{1}$, Sameer Halageri ${ }^{1}$, Prof. Arun K. Singh ${ }^{2}$, \\ Vijay Kumar², Brijesh Mishra², D. N. Upadhyaya²
}

Received: 17 October 2020 / Accepted: 1 November 2020 / Published online: 20 January 2021

(C) The Author(s) 2021. This article is published with open access at https://journal.astes.org.al

\begin{abstract}
Introduction: Hand injuries are the most complex injuries when compared to other bodily injuries. A better understanding of the biological, behavioral, and socioeconomic risk factors that are associated with hand injuries is therefore needed. This data can help identify individuals at risk and define preventive measures to help reduce the incidence.

Material and Methods: We present a study of 350 consecutive patients of hand injury treated between 2017- 2018. The demographic profile of the patient along with the type \& cause of the injury sustained, hand dominance, type of procedure, and requirement of hospital administration was extracted from hospital records.

Results: 159 (45.5\%) of the patients were in the age group of fewer than 20 years. Out of the 350 patients, $288(82 \%)$ were male. 302 $(86 \%)$ patients were right-handed. The most common mode of injury was machine injury in 205 (59\%) patients. $181(52 \%)$ patients had crush injury, $107(31 \%)$ had the sharp cut injury, and 32 (9\%) had blast injury. 94 (27\%) patients needed hospital admission for management. 119 ( $34 \%$ ) patients had the injury to the thumb, $89(25 \%)$ had injury to the middle finger. Primary suturing was done in $116(33 \%)$ patients, tendon and nerve repair in 209 (60\%), and 177 (51\%) patients respectively.

Conclusions: The study describes the demography and etiology of the cases of hand injury. The study has a limitation of having absence of assessment of functional outcome. There is a necessity of hand trauma registry to quantify the burden of hand injuries and formulate a prevention strategy at the national level.

Keywords: demography, hand injury, tendon injury, neurovascular injury,
\end{abstract}

\section{Introduction:}

The hand has an intricate design and is a very peculiar work of anatomy. Any injury to the structures of the hand results in the person becoming handicapped. To minimise this risk, even the smallest hand injuries require good medical evaluation and care. Injuries of the hand need fast and accurate initial evaluation, which allows for medical treatment to be started quickly so that the complications can be reduced.

Original article, no submission or publication in advance or in parallel

\footnotetext{
* Corresponding author:

Sandesh Bharat SINGH

$\bowtie$ dr.sndsh@gmail.com

1 King George Medical College, INDIA.

2 King George Medical College, Lucknow, INDIA
}

Hand injuries are the most complex injuries when compared to other bodily injuries [1].A better understanding of the biological, behavioral, and socio-economic risk factors that are associated with hand injuries is therefore needed. This data can help identify individuals at risk and define preventive measures to help reduce the incidence [2, 3].

In today's societies many daily activities require highly skilled hand work. Hand injuries thus cause major problems for individuals. Hand injuries that require acute medical attention usually deserve special attention as these injuries place a large burden on the healthcare system. There is however limited epidemiological information on hand injuries.

Most studies present in Indian literature are limited to a few centres. The study describes the demography and etiology of the cases of hand injury. It is important to establish targeted strategies for the prevention of hand injuries, thus more information on the occurrence and characteristics of hand injuries is required at a national level through various centres. 


\section{Material \& Methods:}

We present a study of 350 patients of hand injury treated over a period of 2 year. Review of data of patients treated for acute hand injuries in the department was done. Demographic profile of the patient along with other data like the type \& cause of injury sustained, hand dominance, injured hand, type of procedure was extracted from hospital database. Consent was taken. Departmental Review Board Clearance was done.

This is a Retrospective observational study conducted in a tertiary care hospital in north India from June 2017 to May 2019. All patients satisfying the inclusion criteria were included in the study.

\section{Inclusion Criteria:}

a) Hand injuries distal to the wrist.

Exclusion Criteria:

a) Patients with hand injury due to burns.

b) Patients with previous chronic upper limb disease like carpal tunnel syndrome, neuropathy etc.

c) Hand injuries at wrist or proximally.

\section{Results:}

Of the 350 patients' 294 (84\%) of the patients were below 40 years of age. 159 patients were within 20 years of age. 135 patients were between $20-40$ years of age and remaining 56 patients were more than 40 years old (figure 1). Thus showing a huge number of young adults falling victim to injuries.

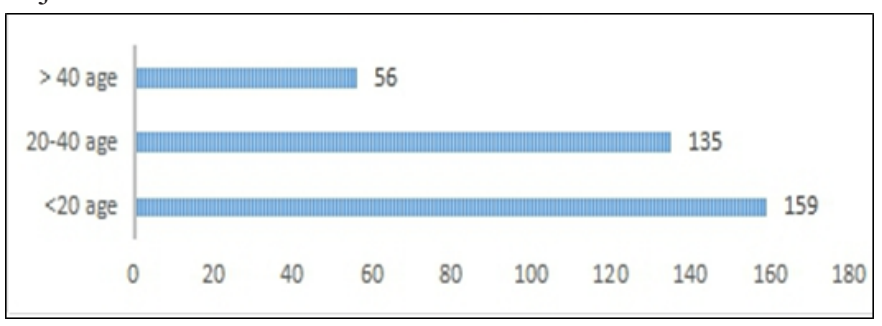

Figure 1: Age Distribution

Of the 350 cases, $288(82 \%)$ patients were male, while $62(18 \%)$ were female (figure 2$)$.

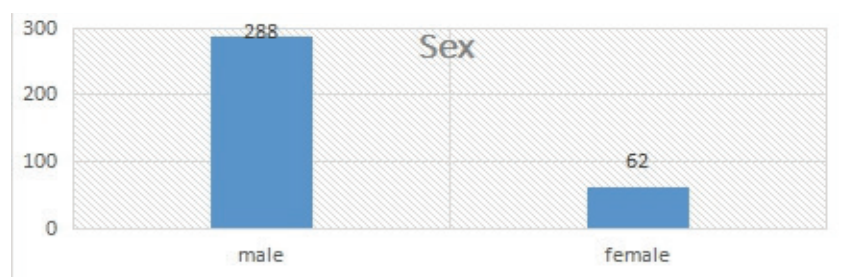

Figure 2: Sex Distribution

$302(86 \%)$ of the 350 patients injured were right hand dominant (figure 3).

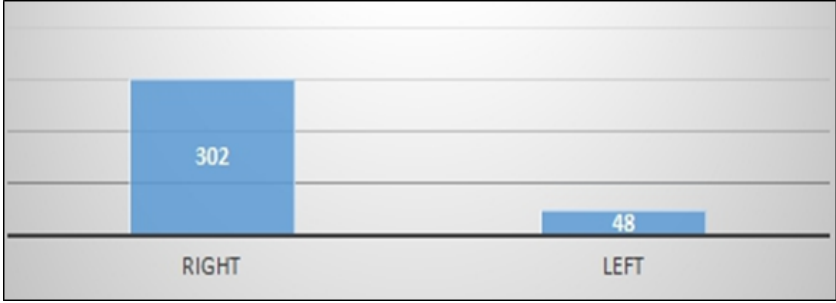

Figure 3: Dominant Hand

$217(62 \%)$ of these 350 patients had suffered injury to the right hand (figure 4).

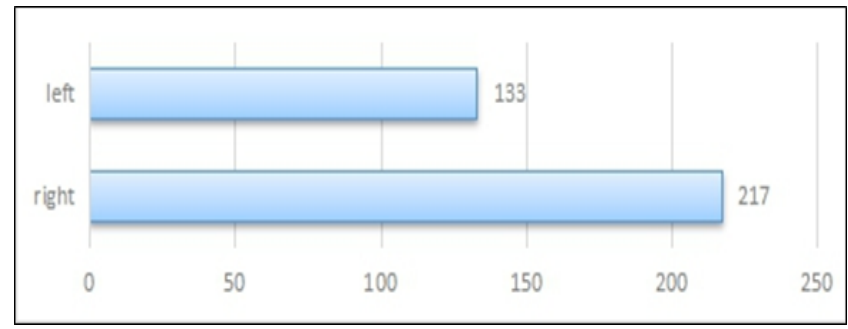

Figure 4: Injured Hand

$256(73 \%)$ of the patients did not require admissions and were treated as outpatients while rest 94 (27\%) required admission for their injuries (figure 5).

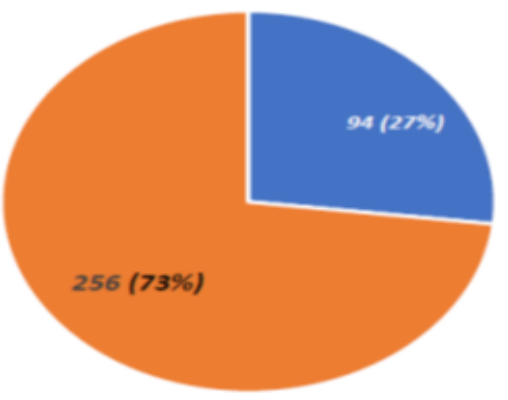

Figure 5: Hospital Admission

The most common mode of injury was machine injury (WMI) in 205 (59\%) patients followed by road traffic accidents (RTA) in $111(32 \%)$, blast or firearm injury (B/FAI) in $32(9 \%)$ and in human and animal bites (H/AB) in 2 patients (figure 6).

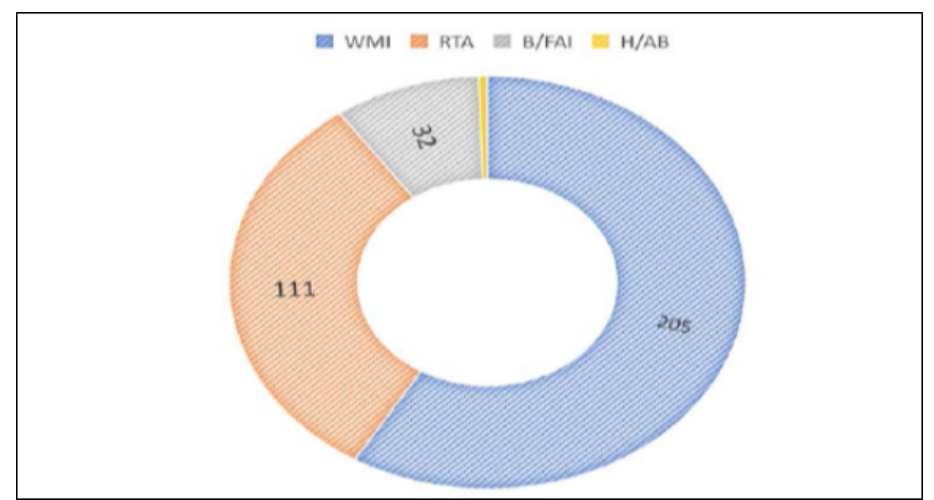

Figure 6: Mode of Injury 
Crush injuries(CI) formed majority of the type of injuries seen in $181(52 \%)$ patients followed by sharp cuts (SC) in $107(31 \%)$, blast injuries (BI) in $32(9 \%)$, avulsion (Av) and degloving (Deg) in 15 patients each (figure 7).

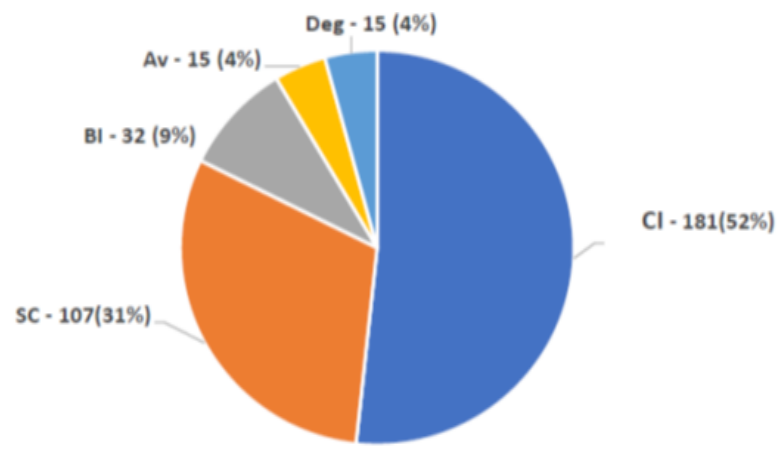

Figure 7: Type of Injury

The most common finger injured was thumb seen in 119 (34\%) followed by middle (89), index (76). ring and little fingers were involved in 52 and 14 cases respectively (figure 8).

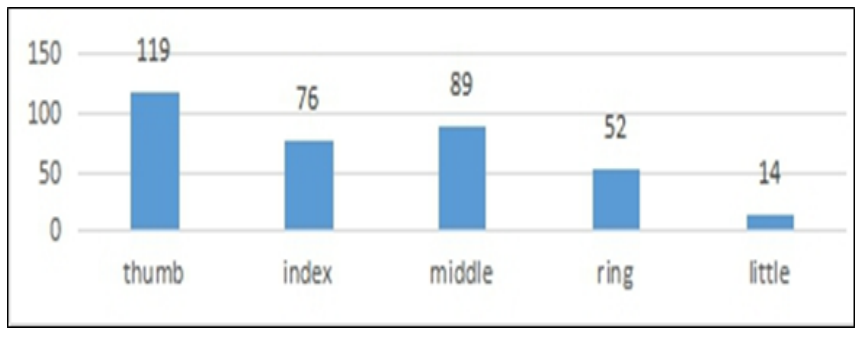

Figure 8: Finger Injured

Most of the injuries and multiple digit injuries and Primary suturing was done in 116 ( $33 \%$ ) patients, the skin grafting in $42(12 \%)$, flap coverage in $96(27 \%)$ patients. $209(60 \%)$ patients required tendon repair and $177(51 \%)$ required nerve repair. Fracture fixation was done in 112 (32\%) patient. Successful revascularisation was done in $65(19 \%)$ patients. $118(34 \%)$ patients were managed with stump closure (figure 9).

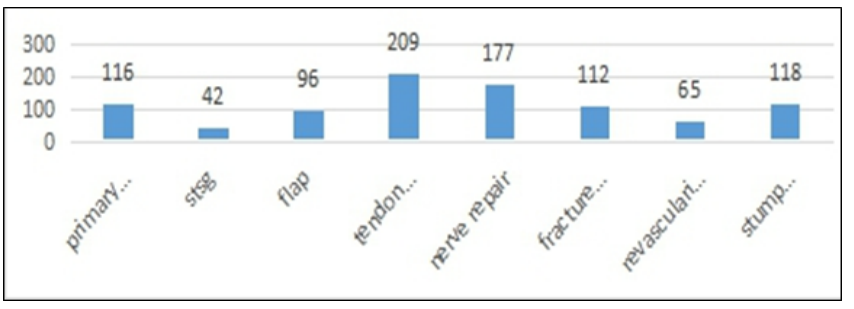

Figure 9: Treatment Given

\section{Discussion}

Epidemiological studies are necessary to determine the requirements of any population to improve the quality of life and health of the citizens of any country.

The epidemiology of hand injuries can provide information about how people are injured, mode and type of injuries and susceptible groups. Hand injuries are considered to be the most frequent body injuries [4], the treatment of which is of long duration and cause social and economic problems.

Trauma to the hand usually presents with multiple soft tissue and bony injuries which are often unrelated. It is important to approach the injured hand with a logical and systematic diagnostic plan which allows the surgeon to recognize the location and severity of the injury and deliver comprehensive primary treatment accordingly. Understanding the mechanism of trauma and the injury patterns will help in guiding surgical reconstruction, rehabilitation, and prevention of hand injuries [5].

It has always been challenging to assess and treat crushed hand. These are combined injuries that can lead to sub optimal functional recovery based on the severity of the tissue trauma [6]. Spontaneous and aggressive initial management afford the best chance to optimize results. The basis of primary care is the identification of the pathoanatomy, assessment of the magnitude of the injury, and focused treatment in the context of the complete injury.

The spectrum of hand injuries can range from mild lacerations of fingers to multiple finger amputations and mutilated hand [7]. The medical expenses, loss of time and wages increase dramatically for severe type of injuries. In addition to this, there is tremendous physical and emotional pain.

Hand injuries are one of the common causes of presentation in emergency departments. Patients who require plastic surgical unit care [8] for specialist surgery can be easily identified by a careful history examination and plain X-rays. Criteria for transfer to plastic surgery unit include injury to nerves, tendons or joints, skin loss or complex fractures, injuries requiring skin grafting or reconstruction, and burn injuries [9].

In our study, of 350 cases, $288(82 \%)$ patients were male and $62(18 \%)$ were female. This finding is consistent with most of the other studies that have been conducted. Packer and Shaheen [10] found out that most of the fracture cases in their study were found to be male patients between the age group of 10 to 40 years. Gupta et al [11] in their study, found an expected male dominance in economically viable individuals of 21 to 30 years, which formed $50 \%$ of the patients of which $22.9 \%$ were labourers and students each.

In this study, we found that among the total 350 patients, 159 were in the age group of $<20$ years. Trybus et al [12] found the average age to be 37.0 years $( \pm 15)$ in their study.32 patients were children with blast injuries. Other patients were mostly unsupervised children with chara cutting injuries. The chara cutting injuries in children was more as the machine are available at homes and children are usually unsupervised. Packer and Shaheen [10]. found that hand fractures in their study were most commonly found in the age group of 10 to 40 years.

$302(86 \%)$ patients' sustained injuries were right dominant hand. This was similar to the findings of another 
study. Gupta et al [11] also found in their study that the majority of hand injuries were sustained in the dominant hand. $217(62 \%)$ of these 350 patients had suffered injury to the right hand and $133(38 \%)$ had injuries to their left hand.

Hung et al [13]documented that in their study, crush injuries occurred in $37.8 \%$ of the patients. Bazroy et al also conducted a study in Pondicherry, India in a glass bottle manufacturing plant. They found that the commonest types of injuries were cuts and lacerations (50.1\%). In this study we found that $181(52 \%)$ of the total hand injuries were crush injuries which was also the dominant mode of injury in both genders followed by sharp cuts in 107 (31\%) and blast in 32 $(9 \%)$ patients. Chara cutting hand injuries formed bulk of the cases. The pattern of injury was different compared to injuries presenting to emergency services in the west [14].

In our study, out of the total cases of 350, 94 (27\%) patients were admitted, 256 (73\%) did not require admission to the hospital and were treated on an out-patient basis or they left against medical advice. Larsen et al [15] found in their study that only a small proportion of the victims were admitted into hospital. They went on to state that most of the injuries in their study were due to leisure activities and the severe injuries were due to occupational accidents.

The most common finger injured was thumb seen in 119 (34\%) followed by middle (89) as compared to index finger seen in the study by Gupta et al. [11] Banhiam Carey Kharrngi, Darpanarayan Hazra et al [16] also found index finger to be the most commonly involved finger.

Primary suturing was done in $116(33 \%)$ patients, skin grafting in $42(12 \%)$, flap coverage in $96(27 \%)$ patients. $209(60 \%)$ patients required tendon repair and 177 (51\%) required nerve repair. Fracture fixation was done in 112 $(32 \%)$ patient. Successful revascularisation was done in $65(19 \%)$ patients. $118(34 \%)$ patients were managed with stump closure. Bharghav desai et al [17] showed that out of the 129 patients that needed operative intervention; $27(20.93 \%)$ required amputation whereas rest 102(79.07) required some orthopaedic intervention.

It is noted that the psychological impact of a visible injury is significantly higher than non-visible disability. Plastic surgeons have a huge role in reducing the patient's psychological stress by correcting and improving the appearance of the injured hand wherever possible. However, this parameter was not included in our study.

Improvement in health and safety practices and legislation's have reduced the incidence of mangling hand injuries in developed countries, however in developing countries, such recommendations are often flaunted.

The pattern of hand injuries in the developed world differs from the pattern of hand injuries in the developing world. In developed countries, leisure activities and sports are the leading cause of hand injuries. In developing countries like India, the leading cause of hand injuries is by far occupational injuries.

Most significant limitation of this study was the lack of proper and adequate follow up of the study subjects. These studies require meticulous documentation. There may be a need for multicentric data with formation of unique code system for simple documentation similar to the ICD system for hand injuries.

Hand injuries are seen to occur in high numbers in the young population causing significant morbidity. Thus a need for preventive strategies is required to minimize it. There should an early response to such injuries with the aim to restore maximum hand function and sensation. To minimize these consequences, emphasis should be put on the workplace, which could reduce the incidence of hand injury by targeting some of its preventable causes. Better training of surgeons in hand care to offload the burden on central institutions [18].

Furthermore, improving access to specialist hand surgery care could help to promptly and appropriately treat those injuries that cannot be prevented.

Hence in conclusion, hand injuries are important because of their consequences, such as permanent disability and their high treatment costs. This study points out many important risk factors, modes and types of injuries and grade of injury. The inclusion of medical records from hospital data into national database will help in the prevention of these injuries, and help in development of diagnosis, treatment and rehabilitation.

\section{Conclusions:}

The study describes the demography and etiology of the cases of hand injury. The study has a limitation of having absence of assessment of functional outcome. There is a necessity of hand trauma registry to quantify the burden of hand injuries and formulate a prevention strategy at the national level.

COI Statement: This paper has not been submitted in parallel. It has not been presented fully or partially at a meeting or podium or congress. It has not been published nor submitted for consideration beforehand.

This research received no specific grant from any funding agency in the public, commercial, or nonprofit sectors. There are no relevant or minor financial relationships from authors, their relatives or next of kin with external companies.

Disclosure: The authors declared no conflict of interest. No funding was received for this study.

\section{References}

1. Ghiya MN, Murty S, Shetty N, D'Cunha R. A descriptive study of hand injuries presenting to the adult emergency department of a tertiary care centre in urban India. J Emerg Trauma Shock. 2017;10:19-25.

2. Larsen, C.F., Mulder, S., Johansen, A.M.T., and Stam C. The Epidemiology of hand injuries in the Netherland and Denmark. European Journal of Epidemiology. 2004; 19, 323327. 
3. Aksan, A.D., Ada, R.D.S., Kayalar, M., Aksu, F. and Bal, E. Epidemiology of injuries treated at a hand and Microsurgery Hospital. Acta Orthopaedic et Traumatological Turcica. 2010; 44 (5), 352-360.

4. Ghosh S, Sinha RK, Datta S, Chaudhuri A, Dey C, Singh A, et al. A study of hand injury and emergency management in a developing country. Int J Crit Illn Inj Sci. 2013;3:229-34.

5. Graham TJ. The exploded hand syndrome: logical evaluation and comprehensive treatment of the severely crushed hand. J Hand Surg. 2006; 31A:1012-1023.

6. Sandzen SC., Jr Crush injuries of the hand and fingers. I. Med Trial Tech Q. 1972; 19:144-151.

7. Samuel CH, Jason AC, David GD, Alexander YS. The economic impact of electrical saw injuries to the hand. J Hand Surg. 2009; 34A:886-889.

8. Rea S, Jones D, Eadie PA. Establishing a plastic surgery trauma clinic. Ir Med J. 2004; 97(4):106-107.

9. Murphy SM, Whately K, Eadie PA, Orr DJ. Unnecessary inter-hospital referral of minor hand injuries: a continuing problem. Ir J Med Sci. 2010; 179:123-125.

10. Packer GJ, Shaheen MA. Patterns of hand fractures and dislocations in a district general hospital. J Hand Surg British European. 1993; 18(4):511-4.

11. Gupta A, Gupta AK, Uppal SK, Mittal RK, Garg R, Aggarwal N. Demographic profile of hand injuries in an industrial town of North India: a review of 436 patients. Indian J Surg. 2013; 75(6):454-61.
12. Trybus M, Tusinski M, Guzik P. Alcohol-related hand injuries. Injury. 2005; 36(10):1237-40.

13. Hung LK, Choi KY, Yip K, Chan J, Leung PC. Recent changes in the pattern of hand injuries in Hong Kong: a regional hospital survey. HKMJ. 1997; 3(2):141-8.

14. Hultman CS, Erfanian K, Fraser J, Thornton SJ, Calvert CS, Cairns BA. Comprehensive management of hot-press hand injuries: long-term outcomes following reconstruction and rehabilitation. Ann Plast Surg. 2010; 64:553-558.

15. Larsen CF, Mulder S, Johansen AMT, Stam C. The Epidemiology of hand injuries in the Netherlands and Denmark. European J Epidemiology. 2004; 19(4):323-7.

16. Banhiam Carey Kharrngi, Darpanarayan Hazra et. A retrospective study on the clinical profile of patients with open hand injury presenting to the emergency department of a tertiary care center in South India. Current medical issues journal. 2019; 17; 98-102.

17. Dr. Bhargav Desai, Dr. Harsha Makwana et al. Epidemiology of hand injuries in adults presenting to a tertiary trauma care center: A descriptive study. International Journal of Orthopaedics Sciences. 2018; 4(1): 434-438.

18. Bajracharya S, Shrestha S. Epidemiology of hand injuries in a tertiary care center. Journal of the universal college of medical sciences. 2017; 5(16): 35-39. 